\title{
$\begin{array}{lllllllll}\mathrm{I} & \mathrm{N} & \mathrm{S} & \mathrm{T} & \mathrm{I} & \mathrm{T} & \mathrm{U} & \mathrm{T} & \mathrm{E}\end{array}$
}

\section{Rural Workers More Likely to Work Nontraditional Shifts}

\author{
ROGELIO SAENZ
}

W orkers in rural areas have historically worked at different times of the day compared to their counterparts in urban areas. Indeed, rural life has been commonly associated with rising early to get the workday underway. This brief presents a snapshot of the rural workforce around the clock. ${ }^{1}$

Key results from the analysis include the following:

- Workers in urban areas are more likely than those in rural areas to arrive at work during the traditional times of 8 a.m. to noon (Figure 1).

- In contrast, rural workers are more likely to get to their jobs at all other times. This is especially true among those arriving at work between 2 a.m. and 6 a.m. and between 9 p.m. and midnight, when they are at least 20 percent more likely than average to begin their workday.

Figure 1: Relative RATIO OF NONMETROPOLITAN AND METROPOLITAN WORKERS BY TIME ARRIVED AT WORK

\section{RELATIVE RATIOS EXPLAINED}

Figure 1 shows the degree to which rural and urban workers are represented across the clock based on when they arrive at work. Overall, rural workers account for 16.1 percent of all workers in the United States regardless of when they arrive at work, while urban workers account for 83.9 percent of the nation's workforce. We obtained the percentage distribution of workers based on rural and urban residence for each of the 24 hours in the day. The percentage of the workforce that is composed of rural residents for each of the 24 hours is then divided by the overall presence of rural workers ( 16.1 percent) regardless of time. To illustrate, while rural workers account for 16.1 percent of the overall workforce, they account for 22.2 percent of workers who arrive at work between 10:00 p.m. and 10:59 p.m. Thus, by dividing 22.2 percent by 16.1 percent, we can determine that rural workers are 1.3 times more likely to arrive at work between 10:00 p.m. and 10:59 p.m. compared to their overall presence in the workforce (i.e., they are overrepresented by 30 percent at this time slot). In contrast, while urban workers constitute 83.9 percent of the overall workforce, they account for 77.8 percent of workers who arrive at work between 10:00 p.m. and 10:59 p.m. Hence, by dividing 77.8 percent by 83.9 percent we obtain a ratio of 0.93 , indicating that urban workers are underrepresented by 7 percent during the 10:00 p.m. to 10:59 p.m. starting time slot.

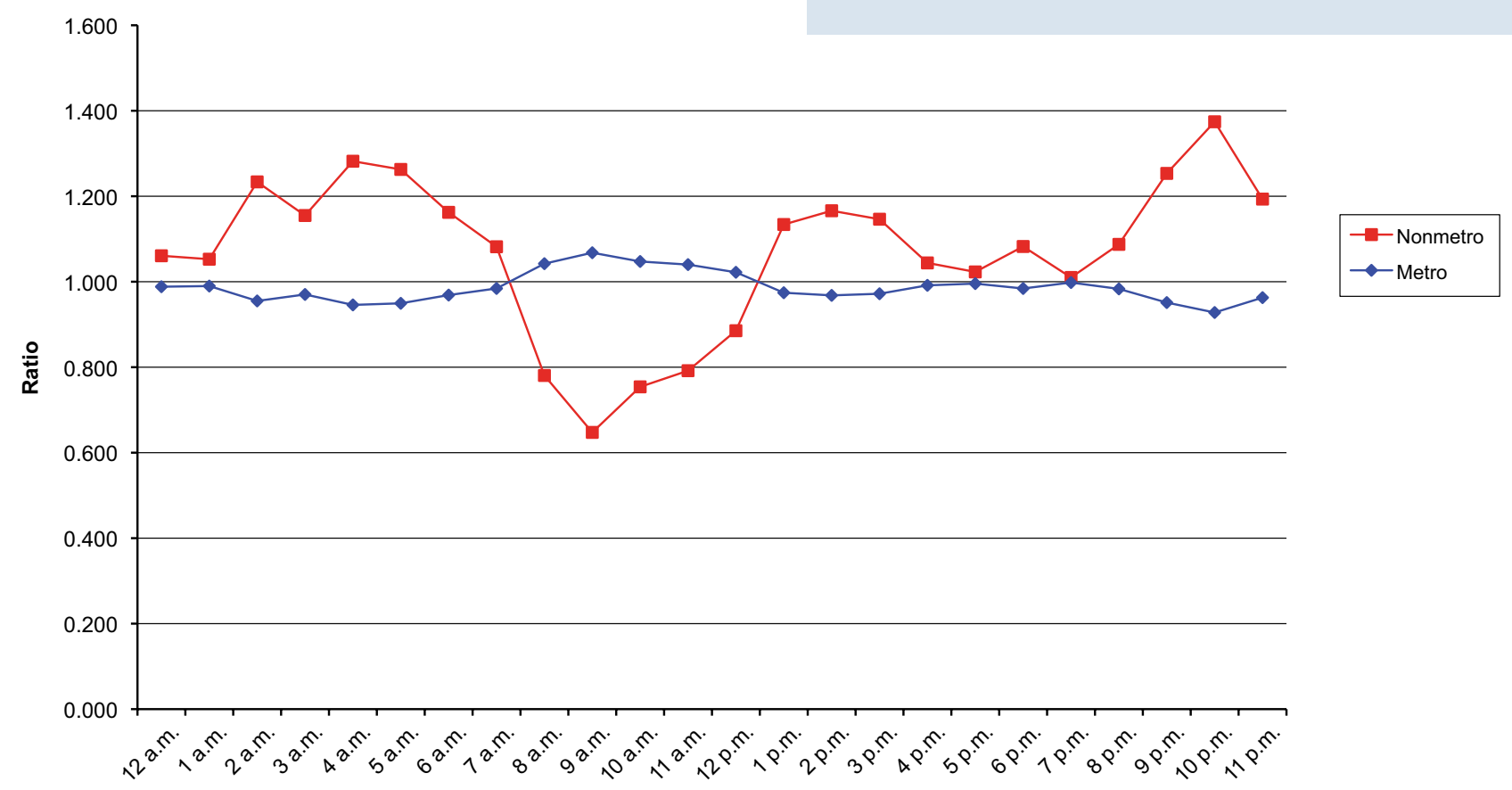


There are some regional variations in the time that rural workers begin their workday. For example, those in the South tend to be the most likely to report to work between midnight and 4 a.m. and between 6 p.m. and 9 p.m.; those in the Midwest are the most likely to report to work between $2 \mathrm{a} . \mathrm{m}$. and 4 a.m., 1 p.m. and 6 p.m., and 9 p.m. and 11 p.m. In contrast, workers in the Northeast and West tend to be the most likely to start their workday between 8 a.m. and noon.

\section{Demographic Variations in Rural Workforce across Work Shifts}

We categorize workers into four work shifts based on the time that they arrive at work: (1) 12:00 a.m. to 5:59 a.m., (2) 6:00 a.m. to 11:59 a.m., (3) 12:00 p.m. to 5:59 p.m., and (4) 6:00 p.m. to 11:59 p.m. The rural workforce varies demographically across these four work shifts (Table 1). For instance, workers tend to be the oldest (median age of forty-two) among those in work shifts 1 (12:00 a.m. to 5:59 a.m.) and 2 (6:00 a.m. to 11:59 a.m.). In contrast, the rural workforce is the youngest (median age of twentynine) among those who go to work in the afternoon, a group that includes youth who work part-time after they get out of school.

Rural workers are disproportionately male, with 117 males per 100 females among the rural workforce. However, this is especially the case among workers in the first work shift (12:00 a.m. to 5:59 a.m.), when there are 216 males per 100 females working at that time (Table 1). Males are also disproportionately represented (137 males per 100 females) among the evening shift workforce (6:00 p.m. to 11:59 p.m.).
TABle 1. Profile OF NONMETROPOLITAN WORKERS BY WORK SHIFT

\begin{tabular}{lccccc}
\hline & Shift 1 & Shift 2 & Shift 3 & Shift 4 & \\
Selected & 12:00 a.m. & $6: 00$ a.m. & $12: 00$ p.m. & $6: 00$ p.m. & All Shifts \\
Characteristics & to & to & to & to & \\
& $5: 59$ a.m. & $11: 59$ a.m. & $5: 59$ p.m. & $11: 59$ p.m. & \\
\hline Median Age & 42 & 42 & 29 & 38 & 41 \\
Males Per 100 Females & 216.3 & 108.7 & 101.0 & 136.7 & 117.2 \\
\hline
\end{tabular}

Rural workers also vary across work shifts on the basis of race and ethnicity. For example, white workers are more likely than blacks and Latinos to report to work in the most traditional work shift, in other words, those who report to work between 6 a.m. and noon (Figure 2). However, black and Latino workers tend to be more likely than whites to arrive at work at all other times. Latinos are the most likely to work in shift 1 (12:00 a.m. to 5:59 a.m.) and blacks in shifts 3 (12:00 p.m. to 5:59 p.m.) and 4 (6:00 p.m. to 11:59 p.m.).

Similarly, foreign-born workers and those who do not speak English (including those who speak English not well or not at all) are disproportionately part of the first work shift (12:00 a.m. to 5:59 a.m.), and they are also somewhat more likely to be among workers in the third shift (12:00 p.m. to 5:59 p.m.). These workers, however, are the least likely to be working in the most traditional (work shift 2) and evening (work shift 4) shifts.

Figure 2. Percentage distribution of White, Black, AND LATino WORKers by WORK Shift

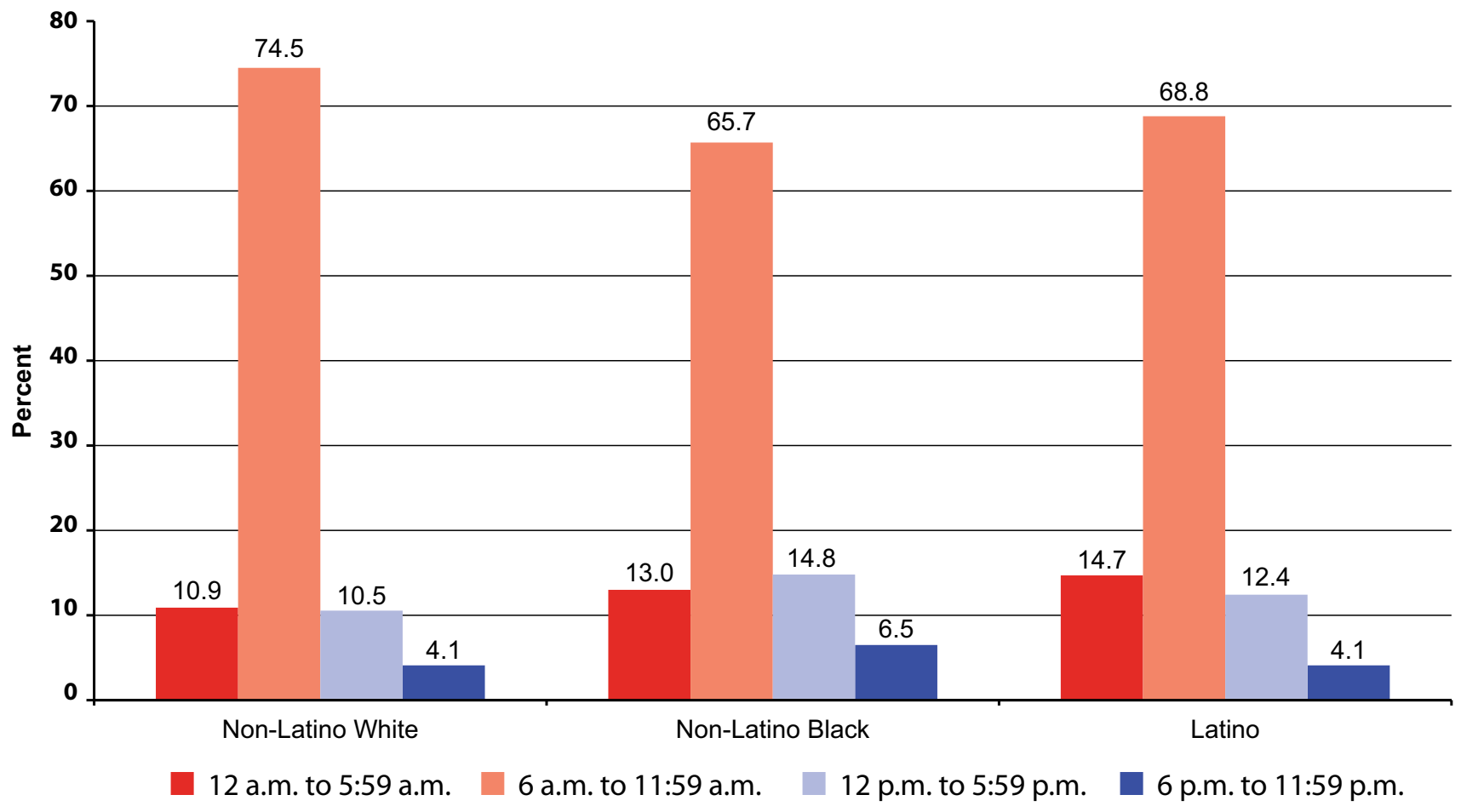




\section{Socioeconomic Variations in Rural Workforce across Work Shifts}

The rural workforce also varies across work shifts on the basis of socioeconomic characteristics. For example, workers in the most traditional work shift (arriving at work between 6:00 a.m. and 11:59 a.m.) tend to have the most favorable socioeconomic profile (high average socioeconomic occupation score, high median hourly wage, and low poverty rate). In contrast, those working in the other three work shifts have less favorable socioeconomic characteristics. The poor are especially represented among workers in work shifts 3 (12:00 p.m. to 5:59 p.m.) and 4 (6:00 p.m. to 11:59 p.m.).

\section{Conclusion}

In summary, rural workers tend to be more likely than their urban counterparts to work during less traditional work periods, such as in the early morning, afternoon, and evening hours. The rural workforce also varies significantly across work shifts on a variety of demographic and socioeconomic characteristics. It is clear, however, that those who tend to be more marginally tied to the labor force (persons of color, the foreign-born, those with English-speaking limitations, and the poor) tend to be more likely to work during the early morning, afternoon, and evening hours. Because social life revolves around the most traditional work shift, those who work at other times of the day run the risk of being further removed from normal life activities. It is important that rural policy makers and community leaders work to ensure that the needs (child care, health care, participation in school activities) of such workers are met.

\section{A T A}

This brief uses recent data from the Census Bureau's 2006 American Community Survey (ACS) 1-Percent Public Use file.

\section{E N D N O T E S}

1. We use the terms rural and nonmetro interchangeably in this brief. The nonmetropolitan (nonmetro) population represents those persons not living in Metropolitan Statistical Areas (MSAs). Metropolitan areas are based on the Census Bureau's definition as of June 1999. Information on the list of counties and New England towns that compose metropolitan areas is available at http://www.census.gov/population/estimates/ metro-city/99mfips.txt. However, the 1 Percent Public-Use file from the 2006 American Community Survey does not identify the metropolitan/nonmetropolitan residence of approximately 10 percent of persons included in the sample. This segment of the sample is excluded from the analysis presented here. 


\section{A BOUT THE AUTHOR}

Rogelio SAenz is a policy fellow at the Carsey Institute and a professor of sociology at Texas A\&M University.

\section{CARSEY \\ I N S T I T U T E}

Building knowledge for families and communities

The Carsey Institute conducts policy research on vulnerable children, youth, and families and on sustainable community development. We give policy makers and practitioners timely, independent resources to effect change in their communities.

This work is supported by the Annie E. Casey Foundation's initiative to strengthen rural families and by the W.K. Kellogg Foundation.

\section{Huddleston Hall}

73 Main Street

Durham, NH 03824

(603) 862-2821

www.carseyinstitute.unh.edu

\section{ANIVERSITY}

